\section{Looting and vandalism threaten Afghanistan's seed distribution}

\section{Natasha McDowell, London}

Efforts to revive war-ravaged agriculture in Afghanistan are being threatened by the country's continuing lawlessness, participating scientists say.

"It is difficult to work effectively because some people with political objectives want to create terror and stop others being helped," says Nasrat Wassimi, a plant biologist who is field coordinator of an international attempt to help Afghan farmers (see Nature 417, 7; 2002).

Wassimi, who is based in Kabul, admits to fears that recent violence, including an assassination attempt on President Hamid Karzai on 5 September, could be a harbinger of renewed civil war. He says that looting, vandalism and the influence of local warlords are complicating the project's attempts to get seed to farmers for this autumn's planting season.

"You take two steps forward and one back," says Geoffrey Hawtin, directorgeneral of the International Plant Genetic Resources Institute in Rome, part of the Future Harvest network of laboratories that is organizing the effort. "But the alternative is to do nothing."

In spring, the consortium delivered wheat seed to 70,000 farmers in 11 provinces. Now multiplied, this and extra imported seed is being redistributed in time for the larger autumn planting. The project's other priority is the rehabilitation of 22 agricultural stations that have been destroyed over the past 25 years.

Wassimi says that it is essential that traditional and imported varieties of seed are tested so that the most suitable ones can be planted in different regions. Afghanistan's traditional crop varieties are highly diverse, partly because of the many microclimates of its mountain ranges.

After the national seed bank was destroyed in 1992, Wassimi spent two years collecting seed from around the country, and hid it in basements in Jalalabad and Ghazni. But looters destroyed the collection last year, stealing the seeds' plastic containers. At the Darul Aman agricultural station, looters also stole water pumps, and vandals dumped stones into wells, which had to be redug.

Wassimi says he can understand the looting, but not the vandalism. "Whatever destruction you see in Afghanistan, a quarter can be attributed to bombing and shelling, but the rest is vandalism," he observes gloomily. "Some days I feel depressed, but I read a book on positive thinking. That, and wanting to help the farmers, keeps me going."

\title{
Early Einstein manuscript set to make a relative fortune
}

\section{Alison Abbott}

Got half a million dollars to spare? If so, you could become the owner of a manuscript that helped to reveal the contribution of Michele Besso, Albert Einstein's lifelong friend and collaborator, to the development of the general theory of relativity.

The 1913 Einstein-Besso Working Manuscript, containing more than 50 pages of handwritten text by Einstein and Besso, is part of a private collection of letters, manuscripts and books on twentieth-century theoretical physics that is due to be auctioned by Christie's in New York on 4 October.

Built up by publishing millionaire Harvey Plotnick, the Harvey Plotnick Library on the Development of Quantum Physics and the Theory of Relativity is considered the world's most important private collection of papers on modern physics. It includes around 2,500 items written by more than 100 of the twentieth century's most significant physicists. The total value of the collection is estimated at around US\$2 million.

The Einstein-Besso Working Manuscript, which Christie's hopes will fetch between $\$ 500,000$ and $\$ 700,000$, is the collection's crown jewel. Besso, a Swiss engineer, was Einstein's most dependable soundingboard. The manuscript includes mathematical calculations, carried out by Besso under Einstein's guidance, which test whether early versions of Einstein's general-relativity equations could account for an anomaly in Mercury's orbit that Newton's theory of gravity couldn't fully explain.

The equations failed to solve the problem, but reformulated equations, finalized in 1915, were eventually successful. Along with other items of correspondence still held by the Besso family, the manuscript has helped science historians to piece together the working relationship between Einstein and Besso.

"Besso contributed more to the intellectual development of Einstein's general theory of relativity than has previously been realized," says Jürgen Renn, a director of the Max Planck Institute for the History of Science in Berlin, and co-editor of the fourth volume of The Collected Papers of Albert Einstein (Princeton University Press, 1995), which includes a reproduction of the EinsteinBesso Working Manuscript. Renn, together with Michael Janssen, a science historian at the University of Minnesota, is preparing an article based on another previously unpublished manuscript by Besso, which underlines the significance of Besso's work in the development of the equations.

Other items in the Plotnick library include the doctoral thesis of Henri Becquerel, who

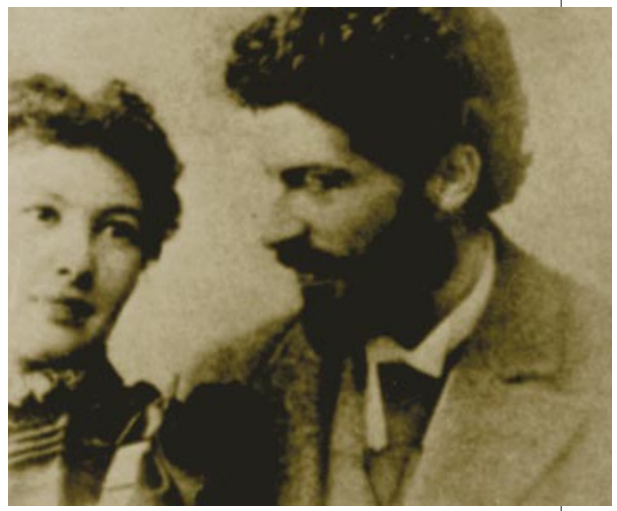

Michele Besso (above right, with his wife Anna) worked with Einstein on his relativity paper.

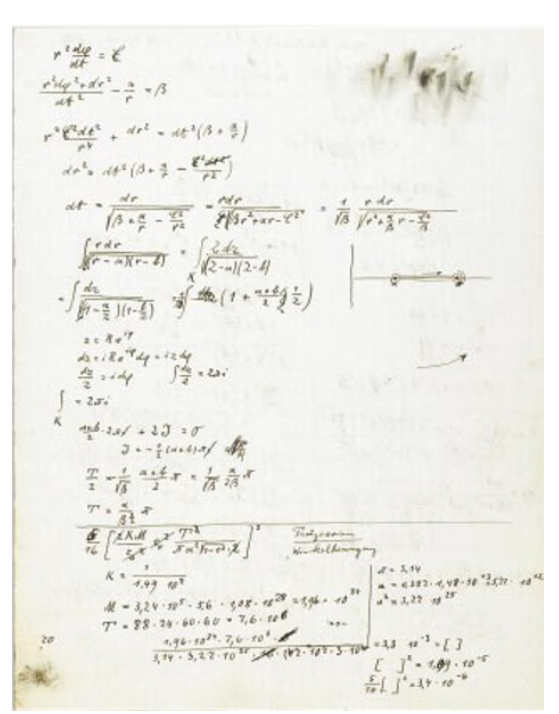

discovered naturally occurring radioactivity, and that of Marie Curie, discoverer of the radioactive elements polonium and radium. There is also an offprint of Wilhelm Röntgen's 1895 announcement of his discovery of Xrays, and three handwritten letters by Werner Heisenberg to the Dutch physicist Samuel Goudsmit, discussing Goudsmit's discovery of electron spin.

Plotnick, who lives in Chicago, started his collection around 20 years ago. "I've always been interested in the history of physics," he says. Having learnt enough about the development of quantum physics, Plotnick is selling in order to concentrate on his new interest in early Islamic art.

Most historians prefer important documents to be held by public institutions to safeguard access, but they accept that private ownership doesn't necessarily hinder their work. Plotnick has already given many historians access to the documents. 